\title{
PHD2: from hypoxia regulation to disease progression
}

This article was published in the following Dove Press journal:

Hypoxia

II April 2016

Number of times this article has been viewed

Abstract: Oxygen represents one of the major molecules required for the development and maintenance of life. An adequate response to hypoxia is therefore required for the functioning of the majority of living organisms and relies on the activation of the hypoxia-inducible factor (HIF) pathway. HIF prolyl hydroxylase domain-2 (PHD2) has long been recognized as the major regulator of this response, controlling a myriad of outcomes that range from cell death to proliferation. However, this enzyme has been associated with more pathways, making the role of this protein remarkably complex under distinct pathologies. While a protective role seems to exist in physiological conditions such as erythropoiesis; the picture is more complex during pathologies such as cancer. Since the regulation of this enzyme and its closest family members is currently considered as a possible therapy for various diseases, understanding the different particular roles of this protein is essential.

Keywords: Hypoxia, PHD, HIF, inflammation, cancer

\section{Introduction}

Molecular oxygen $\left(\mathrm{O}_{2}\right)$ in dry air at sea level makes up $20.9 \%$ of the total atmospheric volume. This corresponds to an $\mathrm{O}_{2}$ partial pressure $\left(\mathrm{PO}_{2}\right)$ of $159 \mathrm{mmHg}$, decreasing with altitude and humidity. ${ }^{1}$ For aerobic organisms, respired atmospheric $\mathrm{O}_{2}$ is diffused into the blood in a hemoglobin-dependent form and reaches the organ systems in the body where it is used as the terminal electron acceptor in the electron transport chain during oxidative phosphorylation in the cells. Consumption of $\mathrm{O}_{2}$ is required to efficiently produce energy for each individual cell in the form of adenosine triphosphate (ATP), and a systemic obstructed supply of this molecule can, therefore, be detrimental to the whole organism.

Eukaryotic organisms have, therefore, developed mechanisms to adapt to changes in $\mathrm{O}_{2}$ levels in their environment in order to maintain metabolic homeostasis. The ability of the body to sense and respond to changing concentrations of oxygen is tightly regulated at the cellular, tissue, and organ levels. The major pathway regulating the response to low $\mathrm{O}_{2}$ tensions involves the activation of hypoxia inducible factor (HIF), a transcription factor identified and characterized in 1992 by Semenza and Wang. ${ }^{2}$ This heterodimeric factor is composed of two basic helix-loop-helix proteins, HIF $\alpha$ and HIF $\beta,{ }^{3}$ which bind to a G/ACGTG motif in hypoxia response elements (HREs) located in the promoter of genes responsible for a plethora of responses such as angiogenesis, erythropoiesis, cell metabolism, viability, and proliferation. ${ }^{4-6}$ 
Expression of HIF $1 \alpha$ occurs in an ubiquitous manner, whereas the expression of HIF $2 \alpha$ seems to be more restricted to certain cell types, including cardiomyocytes, hepatocytes, endothelial cells, glial cells, and interstitial cells of the kidney. ${ }^{7}$ Both isoforms have overlapping functions but are also involved in the regulation of distinct sets of genes. ${ }^{8}$ Accordingly, HIF1 is associated with metabolic changes and vascular responses, whereas HIF2 has been described as the major regulator of erythropoiesis..$^{9,10}$

While the HIF $\beta$ subunit is constitutively expressed, HIF $\alpha$ is regulated posttranscriptionally in an oxygen-dependent manner. Under normoxia, HIF $\alpha$ is hydroxylated at either an asparaginyl residue by the factor inhibiting HIF (FIH) ${ }^{11}$ or at specific proline residues by prolyl-4-hydroxylase domains (PHDs), ${ }^{12}$ in both cases resulting in its inactivation. PHDs hydroxylate either the proline residue on the oxygendependent degradation domain at the $\mathrm{N}$ - or C-termini (NODDD and CODDD, respectively) of HIF $1 \alpha$ and HIF $2 \alpha$. Hydroxylation occurs at Pro402/Pro564 and Pro405/Pro531 residues of each of these isomers ${ }^{13,14}$ and leads to their recognition by the von Hippel-Lindau tumor suppressor protein (VHL). ${ }^{15-17}$ This protein mediates HIF $\alpha$ ubiquitination, targeting this subunit for proteasomal degradation by the $26 \mathrm{~S}$ proteosome. ${ }^{18}$

As PHDs require $\mathrm{O}_{2}, \mathrm{Fe}(\mathrm{II})$, ascorbate, and 2-oxoglutarate (2-OG, an intermediate of the tricarboxylic acid [TCA] cycle) as cosubstrates to exert their functions, ${ }^{19}$ under hypoxic conditions they are rendered nonfunctional and HIF $\alpha$ is stabilized. This subunit then translocates to the nucleus where it binds to HIF $\beta$, inducing the direct transcription of $>1,000$ downstream genes. ${ }^{20-22}$ In the past 15 years, a substantial amount of knowledge has been acquired on the role of the PHDs with regard to hypoxia-related and unrelated proteins. Accordingly, this review aims to discuss recent findings on these essential enzymes, with a focus on PHD2, and the detrimental impact of their deregulation.

\section{HIF prolyl-4-hydroxylase domain enzymes}

PHDs were first described $\sim 10$ years after the discovery of $\mathrm{HIF} \alpha^{12,16,17,19}$ and are nonheme enzymes and iron-dependent members of the dioxygenase family. PHDs possess a twohistidine, one carboxylated motif in their catalytic site, which coordinates the Fe(II) in a octahedral geometry. The three remaining coordination sites are occupied by loosely bound water molecules that contribute to the stabilization of the protein in resting conditions. ${ }^{23}$ In the presence of a HIF $\alpha$ substrate, the $\mathrm{H}_{2} \mathrm{O}$ molecules are displaced by both $\mathrm{HIF} \alpha$ and 2-OG, which in turn coordinates Fe(II) to the catalytic center, creating a $\mathrm{Fe}(\mathrm{IV})=\mathrm{O}$ ferryl intermediate bound to the enzyme that induces the hydroxylation of the HIF $\alpha{ }^{24}$

PHD enzymes have a low affinity for $\mathrm{O}_{2}$ (with a $K_{\mathrm{m}}$ of $230-250 \mu \mathrm{M})^{14}$ that is $\sim 2-10$ times above the $\mathrm{PO}_{2}$ observed under physiological conditions, and its turnover is, therefore, highly sensitive to changes in $\mathrm{O}_{2}$ concentration in the tissues, making these proteins well-suited oxygen sensors. ${ }^{25}$

So far, three mammalian PHD isoforms have been described - PHD1-3 - all of which are capable of hydroxylating the HIF $\alpha$ subunit. ${ }^{12,19}$ All isoforms possess a high sequence homology at the C-terminal domain, but not in the N-terminal, and their expression pattern in different tissues is only partially overlapping. ${ }^{26}$ Subcellular localization patterns of each PHD isoform are also distinct. Although PHD1 is exclusively expressed in the nucleus, PHD2 is mainly localized in the cytoplasm, and PHD3 is evenly distributed throughout both cell compartments. ${ }^{27}$ Interestingly, deletion of the nuclear exclusion signal of PHD2 leads to its accumulation in the nucleus and consequent decreased hydroxylation of HIF $\alpha$. This indicates an important role of the cellular localization of this enzyme in its hydroxylation capacity. ${ }^{27-30}$

The different expression patterns of the isoforms indicate that, although all PHDs are able to hydroxylate HIF $\alpha$ subunits, they possess distinct functions. In fact, each isoform has a different affinity for the inhibition of particular HIF $\alpha$ subunits. Although PHD1 shows a preference for HIF2 $\alpha$ under normoxia, PHD2 has a stronger substrate preference for HIF $1 \alpha$ under the same conditions. PHD3, in turn, preferentially degrades HIF $2 \alpha$ under hypoxia. ${ }^{31}$ This isoform is itself a target of HIF $1 \alpha$, and its induction under hypoxic conditions leads to the negative regulation of HIF $2 \alpha{ }^{25}$

As different isoforms are expressed in distinct tissues and have particular affinities for each HIF $\alpha$ subunit, their impact on development and during physiological conditions seems to be unique. Somatic deletion of PHD1 produces viable offspring with reduced exercise tolerance. Mice lacking this isoform show reduced mammary gland proliferation ${ }^{32}$ as well as a shift from oxidative to glycolytic cellular energetics in the liver and skeletal muscle. ${ }^{33}$ PHD1 deletion also results in increased hepatocyte proliferation ${ }^{34}$ and a decreased apoptotic response of the epithelial cells of the colon during colitis. ${ }^{35}$ PHD3 knockout mice in turn show central nervous system changes in innervation and reduced resting blood pressure.

\section{PHD2}

Although knockout mice for PHD1 and PHD3 are viable, the systemic deletion of PHD2 leads to embryonic lethality. 
Knockout mice for this isoform die of placental and cardiac defects between embryonic days 12.5 and 14.5 as a result of an underdeveloped myocardium and trabeculae, as well as poor vascular branching in the placenta. ${ }^{36,37}$ Therefore, only the use of conditional deletion approaches has been possible to study the role of this enzyme in vivo.

Somatic deletion of PHD2 at 6 weeks of age leads to increased vascular endothelial growth factor A (VEGF-A) levels in the serum, with increased angiogenesis, increased erythropoietin (EPO) ( 230-fold), and severe polycythemia. ${ }^{38}$ Interestingly, the hematopoietic progenitor cell population in the liver and spleen of these mice was also expanded, suggesting that the deletion of this protein also activates extramedullary hematopoiesis. ${ }^{36,39}$

The activity of PHDs is regulated at several levels; from transcription to their catalytic activity. While hypoxia is the major inhibitory stimulus of the PHD activity, other elements are responsible for the inhibition of these enzymes, which is of importance for the pharmacological inhibitors that are currently under development. ${ }^{40}$

In this regard, the generation of inhibitory TCA intermediates such as fumarate, isocitrate, and succinate by damaged mitochondria is an important inhibitory factor to the PHD activity, as these molecules compete against 2-OG for the binding to the active site. ${ }^{41,42}$ The mechanism through which these molecules exert their functions is also the one by which current PHD inhibitors such as dimethyloxalylglycine act in the inhibition of these enzymes.

Regulation of PHD2 can also occur by microRNAs. In prostate cancer, mir182 transcription by HIF1- $\alpha$ leads to the targeting and inhibition PHD2, causing a positive feedback loop to further increase HIF signaling, with increased growth of the tumor. ${ }^{43}$

Other proteins have also been shown to interact with and inhibit PHD2 activity. One example of this modulation is the FK506-binding protein 38, which associates with the 26S proteasome and captures PHD2 through its MYND zinc finger domain. This association at the membranes of the endoplasmic reticulum (ER) and mitochondria mediates PHD2 ubiquitin-independent proteasomal degradation, contrary to cytosolic PHD2, which is maintained stable and in an active form. ${ }^{44}$ MAGE-11, a protein expressed in some embryonic tissues and aberrantly reexpressed in distinct tumor types, was also shown to interact with PHD2 and inhibit its activity in a degradation-independent manner, with consequent increase in HIF $1 \alpha$ levels in cancer cell lines. ${ }^{45}$

Finally, PHD2 is positively regulated by the HIF pathway itself, as its promoter contains a HRE region. Under hypoxia, the binding of HIF $1 \alpha$ to this HRE induces the transcription of PHD2, indicating a feedback mechanism under hypoxia that ensures swift removal of HIF $\alpha$ after reoxygenation. ${ }^{46}$ Despite the recent advances in this area, the mechanisms of PHD2 regulation require further investigation.

\section{Interaction with other proteins}

The interaction between PHD2 and the HIF $\alpha$ subunits has been extensively described and has allowed the understanding of the regulation of oxygen pressure at a cellular level. However, during its activation, PHD2 interacts with other proteins in the cell, mainly leading to the strengthening of its activity and consequently more efficient ubiquitination and degradation of HIF $\alpha$. Currently, 28 unique interactors for the human PHD2 isoform have been described and deposited in the BioGRID database. ${ }^{47}$

One of these interactions is with osteosarcoma amplified 9 (OS-9), a lectin with functions in ER quality control that was found to be amplified in sarcomas. This protein interacts with both PHD2 and PHD3, strengthening the complex between these dioxygenases and $\mathrm{HIF} \alpha$, and consequently increasing the degradation of this subunit. Interestingly, OS-9 has also been shown to directly interact with HIF $1 \alpha$, and the presence of this subunit strengthens the interaction between PHD2 and OS-9. Several lines of evidence indicate, therefore, the formation of a complex consisting of PHD2/ PHD3 and HIF1 $\alpha$ associated with OS-9 in the stabilization of the PHD2/PHD3-HIF1 $\alpha$ axis. ${ }^{48}$

Stabilization of the PHD2-VHL interaction has also been described through binding to other proteins. In this regard, LIM-domain containing protein (LIMD1) has been shown to act as a molecular scaffold, binding simultaneously PHDs and VHL and increasing the speed and efficiency of the hydroxylation and consequent ubiquitination of HIF $\alpha$. This tumor suppression protein is able to bind to all three PHD isoforms, and this interaction is observed in both normoxic and hypoxic conditions. ${ }^{49}$ Recently, the rho-related BTB domain-containing protein 3 was also shown to participate in the formation of the complex between PHD2, VHL, and LIMD1. The expression of this protein is reduced in human renal carcinomas, and its deletion in cancer cells has been shown to increase tumor growth. ${ }^{50}$

Another molecular platform between HIF1 $\alpha$, PHD2, and VHL is phospholipase $\mathrm{D}_{1}\left(\mathrm{PLD}_{1}\right)$. This protein catalyzes the hydrolysis of phospholipids to phosphatidic acid, but recent work suggests that the interaction of this protein with the PHD2VHL-HIF $1 \alpha$ complex accelerates HIF $1 \alpha$ degradation under normoxia. However, the enzymatic activity of this protein leads 
to the induction of HIF $1 \alpha$ translation, and this effect seems to prevail over its role in HIF1 $\alpha$ destabilization. ${ }^{51}$

The A kinase anchor proteins (AKAP) are a class of scaffolding proteins found primarily in cardiomyocytes and neurons. These proteins have been shown to tether multiprotein complexes to specific locations in the cell, maximizing the interactions between their individual components. During normoxia, the muscle AKAP (mAKAP) was shown to interact with both PHD2 and PHD3, anchoring HIF1 $\alpha$ with VHL at the perinuclear membrane of cardiomyocytes thereby increasing the HIF $\alpha$ degradation. Under hypoxia, however, mAKAP organizes ubiquitin E3 ligases to stabilize HIF1 $\alpha$ and optimally locate this subunit close to its site of action in the nucleus, thus showing a dual role for this scaffold protein in the hypoxia response regulation. ${ }^{52}$ Another report showed that AKAP12 in astrocytes, important for mouse brain homeostasis and formation of the blood-brain barrier, is able to bind PHD2, HIF1 $\alpha$, and VHL, decreasing HIF transcriptional activity. Conversely, in retinoblastoma cells, the expression of this protein is negligible, which results in an increased HIF $1 \alpha$ and VEGF expression. ${ }^{53}$

Recent work has also described a role of the tumor suppressor runt-domain transcription factor (RUNX3) in the destabilization of HIF $1 \alpha$ through its interaction with PHD2 under hypoxia. Decreased levels of RUNX3 in solid tumors have also been shown to associate with a decreased HIF $1 \alpha$ degradation with consequent increased transcription of angiogenic factors and worse patient outcome. ${ }^{54}$ Another tumor suppressor protein described as an interactor of PHD2 is the inhibitor of growth protein 4. Under hypoxic conditions, both proteins were shown to associate in distinct human myeloma cell lines and inhibit the activity of HIF $1 \alpha$ and consequently the transcription of HIF-target genes such as $I L-8$ and osteopontin. ${ }^{55}$

Finally, PHD2 was shown to associate with p23 via an interaction between its MYND domain and a PXE motif in the latter. This cochaperone of heat shock protein 90 (HSP90) binds to the N-terminus of this HSP, and the association between these three proteins has been described to facilitate the PHD2-catalyzed hydroxylation of HIF1 $\alpha$. Interestingly, HIF $1 \alpha$ is itself a HSP90 client protein, and p23 knockdown has a more pronounced effect in HIF $1 \alpha$ accumulation under hypoxia. Therefore, a close interaction between these two conserved pathways seems to be required, particularly under hypoxic conditions, possibly contributing to a feedback mechanism under chronic hypoxia. ${ }^{56}$

\section{Other PHD2 targets}

Despite the major role of PHD2 in the regulation of the HIF-pathway, this enzyme has also been associated with the regulation of the transcriptional activity of non-HIF proteins. It was postulated that, like PHD1, this isoform has some role in the regulation of nuclear factor-kappa $\mathrm{B}(\mathrm{NF} \kappa \mathrm{B})$, a major inflammatory regulator. The activation of $\mathrm{NF} \kappa \mathrm{B}$ involves the phosphorylation of $\operatorname{I\kappa B} \alpha$ by IKK $\beta$, with consequent dissociation of this protein from $\mathrm{NF \kappa B}$ and activation of the latter. PHD1 interferes with this activation by hydroxylating the IאB kinase (IKK $\beta$ ), therefore impairing the phosphorylation of $\mathrm{I} \kappa \mathrm{B} \alpha$ by this protein. This results in the failure to trigger dissociation of the latter from $\mathrm{NF} \kappa \mathrm{B}$ and consequent inhibition of the activity of this transcription factor. ${ }^{57}$ Indeed, deletion of PHD2 in colorectal cancer (CRC) has been shown to result in increased tumor growth due to increased secretion of interleukin (IL)-8 and angionin in a HIF-independent and NF $\kappa$ B-dependent manner. ${ }^{58}$

Several novel PHD2 targets have been described in recent years. One example of the proline hydroxylation by PHD2 is the eukaryotic elongation factor 2 kinase (eEF2K), mainly activated during stress conditions where ATP is lacking. This kinase is able to phosphorylate eEF2, leading to decreased protein synthesis and, therefore, adjustment of the cell to stress with consequent preservation of ATP and amino acids. PHD2 hydroxylates the proline 98 of eEF2K under normoxia, preventing its proper binding to calmodulin. ${ }^{59}$ The latter activates this kinase, and, therefore, impediment of this interaction keeps eEF2 in its active form. Under hypoxia, this outcome is not observed, eEF2 is phosphorylated and protein synthesis is inhibited. ${ }^{60}$

Because of the critical function of PHD2 in cardiac development, the role of this protein in the heart under physiological and pathological conditions has also been investigated. PHD2, but not PHD1 or PHD3, has been shown to act as a regulator of intracellular cyclic adenosine monophosphate (cAMP) levels in cardiomyocytes. cAMP plays a crucial role in the sarcomere contraction and relaxation and is degraded through phosphodiesterase (PDE)-catalyzed hydrolysis. In this regard, PHD2 hydroxylates PDE4D, targeting this protein for degradation by the ubiquitin-proteasome pathway and leading to an increase in cAMP levels in the cardiomyocytes. ${ }^{61}$ Additionally, PHD2 and PHD3 were found to hydroxylate the thyroid hormone receptor- $\alpha$ (TR- $\alpha$ ), leading to the decrease of its binding to the nuclear receptor corepressor 2 and consequent removal of the transcriptional repression of phospholamban. As the decreased transcription of this protein in the heart leads to an abnormal constitutive activation of calcium/calmodulin activated kinase II, hydroxylation of TR- $\alpha$ by PHD2 or PHD3 has a protective role in this organ. ${ }^{62}$

Moreover, PHD2 has been shown to hydroxylate the $\mathrm{N}$-myc downstream-regulated gene 3 protein (NDRG3), 
targeting it for proteasomal degradation in a VHL-dependent manner under normoxic conditions. This outcome is inhibited in increased lactate levels that accumulate under hypoxia, as this substrate binds to NDRG3, impeding its interaction with VHL. Consequently, under prolonged hypoxia conditions, there is a downstream increase in growth and angiogenesis signaling via the Raf-ERK pathway activation by NDRG3. ${ }^{63}$

The subunit one of RNA polymerase II (Rpb1) is also hydroxylated by PHDs, as it shares a region of homology with the ODDD from HIF $\alpha$. The outcome of this hydroxylation, however, has been subject to controversy. While Kuznetsova et $\mathrm{al}^{64}$ observed that hyperphosphorylation of this subunit leads to its consequent ubiquitination by VHL and proteasomal degradation in PC12 rat pheochromocytoma cells; Mikhaylova et $\mathrm{al}^{65}$ observed that in renal cell carcinoma the hydroxylation of Rpb1 results in the stabilization of this subunit. This resulted in the transcription of genes involved in cell proliferation and mRNA transport and translation, which was reflected in increased tumor growth. ${ }^{65}$ Interestingly, this group also observed that when Rpb1 is highly expressed, its hydroxylation in these cells is mainly mediated by PHD1 and PHD3, with PHD2 having an inhibitory effect on this outcome. Silencing of PHD2 in these cells, therefore, resulted in an increased hydroxylation of Rpb1, associated with an increased malignancy of the tumor. ${ }^{66}$

A list of PHD2 interactors and targets is summarized in Table 1. Although these findings corroborate and highlight the diversity in function of PHD2, there is still controversy regarding the role and consequences of these interactions. Future work is therefore required to better characterize these contacts and unravel their relevance under biological conditions.

\section{The role of PHD2 in pathology Erythrocytosis}

EPO is the main regulator of red blood cell formation, and its dysregulation is associated with pathological conditions such as anemia and kidney failure (under low levels) or erythrocytosis when EPO levels are inappropriately elevated. ${ }^{67}$ This hormone is also involved in the proliferation, differentiation, and inhibition of apoptosis of endothelial cells, neurons, and vascular smooth muscle cells. ${ }^{68}$

The major EPO source under physiological conditions is the kidney, and production of this protein is stimulated by tissue hypoxia in the organ interstitial space. ${ }^{69}$ In healthy state,

Table I PHD2 interactors and targets

\begin{tabular}{|c|c|c|c|}
\hline PHD2 interactor name & Interaction type & Outcome & References \\
\hline OS-9 & $\begin{array}{l}\text { Complex formation with PHD2 or PHD3 } \\
\text { and } \mathrm{HIFI} \alpha\end{array}$ & Increased HIFI $\alpha$ hydroxylation & 48 \\
\hline LIMDI/RHOBTB3 & Complex formation with PHD2 and VHL & $\begin{array}{l}\text { Increased speed and efficiency of the } \\
\text { hydroxylation and consequent } \\
\text { ubiquitination of HIF } \alpha\end{array}$ & 49,50 \\
\hline $\mathrm{PLD}_{1}$ & $\begin{array}{l}\text { Complex formation with } \mathrm{PH} 2 \text {, VHL, and } \\
\text { HIFI } \alpha\end{array}$ & $\begin{array}{l}\text { Accelerated HIFI } \alpha \text { degradation under } \\
\text { normoxia }\end{array}$ & 51 \\
\hline AKAP & $\begin{array}{l}\text { Complex formation with } \mathrm{PH} 2, \mathrm{VHL} \text {, and } \\
\mathrm{HIFI} \alpha\end{array}$ & Increased HIFI $\alpha$ degradation & 52,53 \\
\hline RUNX3 & Interaction with PHD2 & $\begin{array}{l}\text { Increased HIFI } \alpha \text { hydroxylation and } \\
\text { degradation under hypoxia }\end{array}$ & 54 \\
\hline ING4 & Interaction with PHD2 & $\begin{array}{l}\text { Increased HIFI } \alpha \text { hydroxylation and } \\
\text { degradation under hypoxia }\end{array}$ & 55 \\
\hline p23 & Complex formation with PHD2 and HSP90 & Facilitated HIFI $\alpha$ hydroxylation & 56 \\
\hline PHD2 target name & & Outcome & References \\
\hline $\mathrm{IKK} \beta$ & & Inhibition of the NFKB activation & 57,58 \\
\hline eEF2K & & Activation of eEF2 and protein synthesis & 59,60 \\
\hline PDE4D & & Increased cAMP levels & 61 \\
\hline TR- $\alpha$ & & $\begin{array}{l}\text { Negative regulation of the calcium/ } \\
\text { calmodulin-activated kinase II activation }\end{array}$ & 62 \\
\hline NDRG3 & & $\begin{array}{l}\text { Decreased growth and angiogenesis } \\
\text { signaling }\end{array}$ & 63 \\
\hline \multirow[t]{2}{*}{ Rpbl } & & Proteasomal degradation of RpbI & 64 \\
\hline & & Stabilization of Rpbl & 65 \\
\hline
\end{tabular}

Abbreviations: PHD, prolyl hydroxylase domain; OS-9, osteosarcoma amplified 9; HIF, hypoxia inducible factor; LIMDI, LIM-domain containing protein; RHOBTB3, rhorelated BTB domain-containing protein 3; VHL, von Hippel-Lindau tumor suppressor protein; PLD, phospholipase $D_{1}$; AKAP, A kinase anchor protein; RUNX3, runt-domain transcription factor; ING4, inhibitor of growth protein 4; eEF2K, eukaryotic elongation factor 2 kinase; HSP, heat shock protein; PDE, phosphodiesterase; cAMP, cyclic adenosine monophosphate; TR- $\alpha$, thyroid hormone receptor- $\alpha$; NDRG3, N-myc downstream-regulated gene 3 protein; RpbI, RNA polymerase II. 
this hormone is present in low amounts in the serum, being upregulated in response to reduced $\mathrm{PO}_{2}$ or stress and leading to increased oxygen delivery through increase of erythrocyte production. The first described relationship between hypoxia and Epo gene expression was by Goldberg et al, ${ }^{70}$ in 1988 , showing a positive correlation between the two. Both the $5^{\prime}$ and $3^{\prime}$ enhancer regions of the EPO gene possess HREs, ${ }^{2,3}$ and activation of the transcription of this hormone has been shown to be HIF $2 \alpha$-dependent. ${ }^{71}$

Various heterozygous point mutations have been described in the human PHD2 gene, which lead to an increase of red blood cell mass and are sometimes also associated with hemorrhages, strokes, and increased risk of thrombosis. ${ }^{72,73}$ The mutations P317R and P371H were shown to affect the catalytic rate and substrate binding of PHD2, inhibiting partially the hydroxylation of HIF. ${ }^{67}$ In fact, the P317 is located two residues from the $\mathrm{Fe}(\mathrm{II})$-binding residue, in close proximity to the active site, and therefore the mutation in this residue affects not only the substrate binding but also the interaction with Fe(II). ${ }^{74}$ Interestingly, in a heterozygous H374R mutation, in addition to the erythrocytotic phenotype, the patient developed a recurrent paraganglioma that exhibited loss of PHD2 in both alleles. ${ }^{73}$

Several animal models have been used in the last few years to assess the role of the HIF pathway regulators in erythropoiesis. Deletion of either PHD1 or PHD3 does not lead to changes in hematocrit, whereas mice lacking both proteins develop a mild form of erythrocytosis. On the other hand, systemic heterozygosity of PHD2 already leads to induction of hematocrit ${ }^{75}$ and somatic inactivation after birth leads to dramatically elevated serum EPO levels, severe erythrocytosis and early death. ${ }^{36,39}$ Additionally, combined loss of PHD2 and PHD1 or PHD3 can still exacerbate the erythrocytosis phenotype. ${ }^{76,77}$ Although PHD2 is the major regulator of EPO production, combined loss of PHD2 and PHD1 or PHD3 still exacerbates the erythrocytosis phenotype, suggesting a minor role of PHD1 and PHD3 in the regulation of EPO. ${ }^{76,77}$

To model the human P317R mutation, Arsenault et al characterized a mouse line with a P294R knock-in mutation in the $P h d 2$ gene, markedly diminishing this enzymes activity. Mice with one mutated PHD2 allele displayed a degree of erythrocytosis and normal EPO levels equivalent to what was seen in PHD2 heterozygous mice. Interestingly, this phenotype was already reversed in HIF $2 \alpha^{+/}$mice, but not in a HIF $1 \alpha^{+/-}$background, which is consistent with the expanding body of data supporting the critical role of HIF $2 \alpha$ in the regulation of erythropoiesis. ${ }^{78}$
Moreover, our group has established a crucial role for PHD2 as an oxygen sensor for the HIF2 $\alpha$-dependent regulation of EPO along with a protective role for HIF $1 \alpha$ in mice suffering from polycythemia. Mice lacking PHD2 in CD68-expressing cells (eg, all hematopoietic cells, different epithelial cell lineages, and EPO producing cells) $)^{37}$ exhibited an excessive EPO production in both kidney and brain, with severely increased hematocrit (up to 85\%), thrombocytopenia, and splenomegaly. Further deletion of HIF $2 \alpha$ in these mice abolished the erythrocytosis phenotype, whereas deletion of HIF $1 \alpha$ had no effect on the outcome. However, mice lacking both PHD2 and HIF1 $\alpha$ in these cells showed a reduced life span, which we found to be directly linked to the stabilization of HIF $2 \alpha$ by HIF $1 \alpha$-induced PHD3. ${ }^{79}$ The interplay or compensatory effect of different PHD isoforms has, therefore, not only an important role in fine-tuning the HIF activation, but shows that targeting of a few isoforms can ultimately lead to a harmful outcome.

Although the major EPO-producing organ is the kidney, this hormone is also produced to a lesser extent by the liver, neurons, and glial cells. ${ }^{67}$ Accordingly, work based on the deletion of distinct PHD isoforms in the mouse liver has shown that hepatic disruption of all three PHD isoforms in this organ leads to severe erythrocytosis, with extensive vascular malformation and massive accumulation of lipid droplets. ${ }^{80}$ These mice showed reduced EPO production in the kidney, possibly due to a feedback mechanism related to the production of EPO in the liver. Although the presence of a single functional allele of PHD1 or PHD3 minimized the vascular and lipid abnormalities, it was not sufficient to prevent the erythrocytotic phenotype observed in the triple knockout, corroborating the major role of PHD2 in the regulation of EPO levels in this organ and, consequently, erythrocyte production. ${ }^{81}$

PHD2 has a widely accepted role in the inhibition of EPO production, maintaining a tight balance in the red blood cell production. As increased EPO levels contribute to erythrocyte production, PHD2 inhibitors are currently under development for treatment of anemia. ${ }^{40,82,83}$ Current therapies involve the use of recombinant human EPO or erythropoiesis stimulating agents, which are associated with safety concerns such as the development of antibodies against these erythropoiesis stimulating agents and off-target effects that can result in a higher rate of cardiovascular events. PHD inhibition could therefore be beneficial, as it would lead to the reduction of blood pressure and reduction of ischemic injury. ${ }^{83} \mathrm{~A}$ recent phase 2A clinical trial using GSK1278863 showed that administration of this compound for 28 days induced an 
effective EPO response in patients with anemia related to chronic kidney disease (CKD). EPO production occurred in a dose-dependent fashion, but the response rate was higher for the lower administered doses, whereas hemoglobin levels fluctuated only mildly. Administration of high doses of this PHD inhibitor leads to an excessive EPO response. ${ }^{84}$ Therefore, the dosage required for these compounds should be thoroughly investigated. Nevertheless, activation of the HIF proteins has been shown to have a pivotal role in the development of clear-cell renal cell carcinoma, ${ }^{83}$ and a mutation affecting the hydroxylating capacity of PHD2 resulted in the development of a pheochromocytoma in a patient, ${ }^{73}$ indicating that caution is required when considering the use of PHD inhibitors as therapy. In addition, inhibiting this versatile enzyme in other organs at the same time might not be beneficial, as we will discuss in the remainder of this review.

\section{Chronic kidney disease}

Chronic hypoxia in the tubulointerstitial area of the kidney is considered the final pathway that leads to the development of end-stage renal disease ${ }^{85,86}$ The initial response of the renal cells to the hypoxic stimulus is the activation of the HIF pathway. This results in the consequent upregulation of proangiogenic factors such as VEGF, which protects the kidney against capillary rarefaction. ${ }^{85}$ Systemic administration of PHD inhibitors in ischemia reperfusion and Thy 1 nephritis models was shown to lead to increased angiogenesis with reduced cell apoptosis and consequent improved disease outcome. ${ }^{86}$

Interestingly, nephrectomized kidneys from CKD patients revealed a high correlation between HIF $1 \alpha$ expression and low degree of interstitial fibrosis, ${ }^{86}$ whereas in renal biopsy samples from patients with type 2 diabetes and advanced nephropathy, the opposite was observed. ${ }^{87}$ This contradictory outcome is further supported by animal studies using genetically modified mice in which increased HIF $1 \alpha$ expression in the kidney promoted the fibrosis of this tissue ${ }^{83}$ and silencing of HIF $1 \alpha$ ameliorated the disease progression in a chronic ischemic renal injury model. ${ }^{88}$

The role of the HIF pathway in CKD, therefore, needs further investigation, as under periods of brief hypoxia, HIF $1 \alpha$ seems to be protective, but under chronic hypoxia, the outcome of HIF activation appears to be deleterious. ${ }^{88}$ Continued hypoxia in the kidney ultimately results in the destabilization of HIF $1 \alpha$ m RNA, while HIF2 $\alpha$ is unaffected by this prolonged low $\mathrm{O}_{2}$ level.

Pharmacological inactivation of PHDs is being considered as a possible therapy for CKD since inhibition of these enzymes prior to renal injury has been shown to ameliorate fibrosis and improve renal function in several models. ${ }^{86}$ However, the continued activation of the HIF pathway upon kidney damage has been shown to contribute to the progression of the disease,,$^{85}$ and therefore, future studies are required to understand the mechanism through which this pathway acts in CKD.

\section{Cancer}

Tumors are rapidly dividing structures that require an increased vascular supply compared to healthy tissues. However, tumor growth frequently surpasses the expansion rate of the vasculature, leading to a deficient supply of nutrients and oxygen in the core of the tumor area. To counteract this, tumor cells secrete excessive amounts of proangiogenic factors, tilting the balance between pro- and antiangiogenic factors toward the first, which then leads to the formation of immature vasculature. ${ }^{89}$ Consequently, the blood vessels growing within the tumor present irregular conformations, being commonly leaky or nonfunctional. ${ }^{90}$ Solid tumors have, therefore, regions under acute or chronic hypoxia; a trait that was first described in the 1950s in the works of Gray et $\mathrm{a}^{91}$ and Thomlinson and Gray. ${ }^{92}$ Oxygen pressures in human tumors can reach extremely low levels, in a range 25 times lower than what can be observed in the representative healthy tissue. ${ }^{93}$ This characteristic hinders radiotherapy, as this treatment is based on the oxidation of cells under aerobic conditions and is, therefore, associated with poor disease prognosis in patients. ${ }^{94,95}$

The adaptation to hypoxia in the tumor tissue involves the induction, repression, or manipulation of genes that regulate angiogenesis, proliferation, immune escape, and metastasis by the HIF pathway. ${ }^{96}$ Therefore, many studies have also focused on the effect of the PHDs during tumor development, which resulted sometimes in opposing effects depending on the tumor type and the PHD isoform. Indeed, an extensive collection of human cancer microarray data (Oncomine database; Thermo Fisher Scientific, Waltham, MA, USA) illustrates these disparities well. ${ }^{97}$ An analysis of the expression profiles of the different PHDs shows that PHD1 is only in $11.2 \%$ of the tested cohorts differentially expressed in tumors compared to the surrounding healthy tissue. On the other hand, the expression level of PHD2 and PHD3 is more often changed in tumor tissue $(17.9 \%$ and $27.9 \%$, respectively) (Table 2). Furthermore, considerably more cases are found where these PHDs are overexpressed, especially in tumors of the lung, liver, and kidney. The most important exception is the expression of PHD2 and PHD3 in 
Table 2 Summary of the three PHD isoform expression profiles in human tumors using a complete set of published human oncology microarray data

\begin{tabular}{|c|c|c|c|c|c|c|}
\hline \multirow{2}{*}{$\begin{array}{l}\text { Analysis type by cancer } \\
\text { Bladder cancer }\end{array}$} & \multirow{2}{*}{\multicolumn{2}{|c|}{$\begin{array}{l}\text { PHDI } \\
\text { Cancer } \\
\text { vs } \\
\text { normal }\end{array}$}} & \multirow{2}{*}{\multicolumn{2}{|c|}{$\begin{array}{l}\text { PHD2 } \\
\text { Cancer } \\
\text { vs } \\
\text { normal }\end{array}$}} & \multirow{2}{*}{\multicolumn{2}{|c|}{\begin{tabular}{|l|} 
PHD3 \\
Cancer \\
vs \\
normal
\end{tabular}}} \\
\hline & & & & & & \\
\hline & & & & & & \\
\hline Brain and CNS cancer & & 4 & 6 & & I & 3 \\
\hline Breast cancer & 10 & 2 & 3 & 3 & 12 & 1 \\
\hline Cervical cancer & & & & & 4 & \\
\hline Colorectal cancer & & 2 & & 14 & & 19 \\
\hline Esophageal cancer & & & & 3 & & 3 \\
\hline Gastric cancer & 2 & & 2 & & & 2 \\
\hline Head and neck cancer & & & 3 & & 3 & \\
\hline Kidney cancer & 3 & & 8 & & 8 & I \\
\hline Leukemia & & 3 & I & 4 & & 4 \\
\hline Liver cancer & & & 3 & & 5 & \\
\hline Lung cancer & & & 3 & & 13 & \\
\hline Lymphoma & & & 1 & 1 & 4 & 3 \\
\hline Melanoma & & & & & & 3 \\
\hline Myeloma & & 1 & 2 & & & 2 \\
\hline Other cancer & I & 2 & 2 & & 5 & 2 \\
\hline Ovarian cancer & & 1 & I & 1 & 2 & \\
\hline Pancreatic cancer & & & I & 1 & 5 & \\
\hline Prostate cancer & & & & & & 2 \\
\hline Sarcoma & & & 2 & & 2 & 2 \\
\hline Significant unique analyses & 16 & 15 & 37 & 27 & 65 & 45 \\
\hline Total unique analyses & 227 & & 357 & & 394 & \\
\hline
\end{tabular}

Notes: The number in each cell under "cancer vs normal" corresponds to the amount of cancer types that contains a significantly different level of PHD2 compared to normal corresponding tissue. Thresholds for significance are $P=0.05$ and fold expression $>1.5$, considering all gene ranks. Red signifies the PHD overexpression or copy gain in the analyses; blue represents the PHD under expression or copy loss. Intensity of color signifies the best rank of PHD2 in those analyses. Cell color is determined by the best gene rank percentile for the analyses within the cell, as represented below:

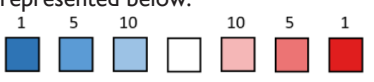

Oncomine $^{\mathrm{TM}}$ (Compendia Bioscience, Ann Arbor, MI) was used for analysis and visualization.

Abbreviations: PHD, prolyl hydroxylase domain; CNS, central nervous system.

the group of CRCs, suggesting for a protective role of both enzymes in this cancer type. ${ }^{58,98}$ Patients with early-stage CRC and low PHD2 expression were shown to have poorer survival than patients who did not display this decrease, and this was in a HIF1 $\alpha$-independent manner. ${ }^{99}$ Furthermore, PHD2 silencing in CRC xenografts results in increased tumor growth due to the activation of the NFKB signaling, with a consequent increase in angiogenesis. This outcome was described by Chan et al ${ }^{58}$ for distinct $\mathrm{CRC}$ cell lines and correlates with the increased tumor vasculature observed in patient samples where PHD2 is reduced. These researchers also suggested that the observed phenotypes driven by PHD2 are HIF- and hydroxylase-independent. ${ }^{58}$

PHD2 expression has also been analyzed in a neuroendocrine tumor of the medulla of the adrenal glands. Although germ-like mutations of PHD2 have been associated mainly with an erythrocytotic outcome, one patient carrying an H374R mutation in the PHD2 gene developed pheochromocytoma. The mutant allele was found in the majority of the tumor cells, indicating a possible tumor suppressive role of PHD2. Accordingly, the described mutation affected the hydroxylation capacity of PHD2, as this residue has a $\mathrm{Fe}(\mathrm{II})$ coordinating function. ${ }^{73}$ So far, this has been the only PHD2-mutation associated with cancer development, but a mutation of $\mathrm{D} 254 \mathrm{H}$ could also be associated with increased cancer predisposition, as this residue is located in the catalytic center of PHD2. ${ }^{100}$

Interestingly, the Oncomine data show a preferential overexpression of PHD1 and PHD3 in breast cancer, the most common cancer among woman (Table 2). For PHD2, results are diverse, which is also reflected in the results of the different PHD2 studies in this type of cancer. In a MCF7 mouse model of hormone-dependent breast cancer, Bordoli et $\mathrm{al}^{101}$ observed a decrease in PHD2 levels, with increased tumor growth through the production of VEGF, Amphiregulin, and IL-8 in a HIF $2 \alpha$-dependent manner. This outcome was also confirmed by Wottawa et a ${ }^{102}$ upon PHD2 silencing in the same model. However, when using a more invasive model (MDA-MB-231), they found a significantly delay and impairment of tumor growth when PHD2 was downregulated. This could be related to a cancer-cell-intrinsic reduction of transforming growth factor (TGF)- $\beta 1$ secretion, with consequent reduced TGF- $\beta$ mediated transcription of osteopontin. Although this outcome suggests a tumor promoting role for PHD2, the mechanisms behind these results are still not fully elucidated. ${ }^{102}$ With regard to breast cancer metastasis, the role of PHD2 has also been investigated. Using a human LM2 xenograft model, Naba et a ${ }^{103}$ observed that increased levels of PHD2 associate with increased metastatic potential. Interestingly, silencing of this protein in the LM2 tumor cells did not affect their tumor invasiveness or fibrosis, but led to reduced metastasis formation, indicating that PHD2 potentially plays a role at a later stage of the metastatic cascade. ${ }^{103}$ The importance of PHD2 in breast cancer metastasis was further confirmed by Kuchnio et al, ${ }^{104}$ using a spontaneously arising PyMT-oncogene driven breast cancer approach (MMTV-PyMT). In this model, PHD2 haplodeficiency in 
the tumor cells had no influence on the tumor growth but led to a significant reduction in the metastasis number in the lung. This outcome was the result of a decreased secretion of TGF- $\beta$ by the cancer cells, leading to a decreased activation of the cancer-associated fibroblasts (CAF). Heterozygous deletion of PHD2 in the CAFs did not alter their activation, indicating that PHD2 might have a role in metastasis of breast tumor cells via a paracrine effect on the tumor microenvironment (TME). ${ }^{104}$

Finally, work performed in our lab using several mouse tumor cell lines (Lewis lung carcinoma [LLC] model, B16 melanoma, and LM8 osteosarcoma) showed that ablation of PHD2 resulted in higher vessel density, surprisingly followed by a significant reduction in tumor growth. Interestingly, inhibition of proliferation of the tumor cells occurred by an increased matrix metalloproteinases (MMP) activity, ${ }^{105}$ with consequent release of TGF- $\beta$ from the TME that in turn had an antiproliferative effect on the tumor cells in a strongly dose-dependent manner. ${ }^{106}$ This described effect occurred in a HIF-independent manner and presented evidence for a role of PHD2 in the malignant transformation of TGF $\beta$, paving the ground for future studies on the interaction between HIF regulators and growth factors in tumors.

\section{PHD2 in the TME}

The crosstalk between cancer cells and their surrounding microenvironment has been recognized as a detrimental factor in cancer development and progression. Consequently, the role of the HIF pathway in the TME has also been investigated in the last years, as the endothelial and epithelial cells, fibroblasts, and immune cells surrounding the tumor are subjected to an identical hypoxic stress as to the tumor cells. ${ }^{107}$

As neovascularization represents one of the major steps in tumor growth and development, the study of the role of PHD2 in the endothelial cells is one of the major points of interest. In fact, deletion of only one PHD2 allele in the endothelial compartment has led to the increase of VE-cadherin in the endothelial junctions as well as of the soluble VEGF trap sFlt in a HIF $2 \alpha$-dependent manner. This allows for an increased stabilization of the tumor vessels, leading to a better perfusion of the tumor, consequently decreasing hypoxia and therefore the malignancy and metastasis formation. ${ }^{75,108}$

CAFs represent one of the major cell populations in the tumor stromal environment. These cells promote tumor survival and cancer cell dissemination through the secretion of growth factors and protumor chemokines, as well as MMPs. ${ }^{89}$ Madsen et al ${ }^{109}$ observed that prolonged exposure to hypoxia deactivates CAFs, which consequently led to reduced remodeling and stiffening of the surrounding extracellular matrix. When coinjecting of 4T1 with CAFs into nude mice, specific PHD2 inhibition in the CAFs prevented tumor cell invasion and metastasis to lung and liver, suggesting a detrimental role for PHD2 in these cells in promoting metastasis formation. ${ }^{109}$

Inflammation represents the seventh hallmark of cancer, as inflammatory cells are recruited by the tumor and contribute to its initiation, promotion, progression, and metastasis. ${ }^{10,111}$ The major cells associated with the TME are the tumor-associated macrophages, which switch from an antitumor profile (M1) to an alternatively activated protumor nature (M2) once recruited to the tumor. These cells contribute to the stimulation of tumor growth, invasion, and metastasis as well as neoangiogenesis, while preventing the antitumor response by other inflammatory cells. ${ }^{89}$ The plasticity between these two phenotypes has a crucial role in the development of cancer and has been described to be HIF-related. ${ }^{107}$

Cytotoxic T-cells also play an important role in immune surveillance and tumor prevention in both mouse and human cancer. HIF $1 \alpha$ activation in T-cells is associated with a detrimental effect during cancer, as this outcome has been negatively correlated with T-cell receptor signal transduction. ${ }^{107}$ Regulatory T-cells are able to suppress the functions of the antitumor cytotoxic T-cells, allowing further development of the tumor. ${ }^{107,111}$ HIF $1 \alpha$ has been shown to enhance the differentiation of Th17 cells and inhibit regulatory T-cell development, possibly contributing to distinct outcomes when activated in distinct T-cell subsets. ${ }^{112}$

Nevertheless, although a lot of work has been focused on the role of HIF $1 \alpha$ and HIF $2 \alpha$ in inflammatory cells during the progression of cancer (for reviews, see Mamlouk et $\mathrm{al}^{113}$ and Kumar and Gabrilovich ${ }^{111}$ ), little is known about the role of PHD2 in these cells in the TME. Our group has shown that deletion of PHD2 in both the myeloid and T-cell compartment results in a decreased tumor volume in LLC and B16 tumor models. This outcome was not observed in the deletion of PHD2 in either compartment alone and was due to the decreased general production of cytokines by both tumor associated macrophages and T-cells, not affecting their recruitment to the tumor area. Both pro- and antiinflammatory cytokines were found to be decreased, indicating that PHD2 deletion has an effect in multiple pathways, with an antitumoral net effect. ${ }^{113}$

The role of PHD2 in cancer progression is still controversial, and further advances in this area will be required to better characterize the effects of this enzyme in the individual cancer 
types. A deeper understanding of the role of PHD2 in all cells that constitute the tumor mass is in this regard particularly relevant in light of pharmacological PHD2 blockade.

\section{Inflammation}

\section{Ischemia}

Vascular stenosis leads to the reduction of blood supply to tissues and consequent ischemia that translates in tissue dysfunction and necrosis. The resulting shortage of oxygen and glucose required for cellular metabolism leads to an adaptive response involving the activation of the HIF pathway, and therefore the effect of PHD2 in this pathology has been a target of investigation. Using PHD2 short interfering (siRNA), Natarajan et al $^{114}$ observed a stabilization of HIF1 $\alpha$ in the myocardium of mice subjected to an acute model of heart ischemia. These cells showed increased production of inducible nitric oxide synthase, and the infarct size in the tissue was reduced, suggesting an NO-dependent cardioprotection mechanism possibly preventing cardiomyocyte cell death. ${ }^{114}$

Accordingly, Kunze et al ${ }^{115}$ observed an improved outcome with decreased infarct size from acute ischemic stroke upon PHD2 deletion when employing a model of neuron-specific knockout of PHD2. In this study, however, this outcome was HIF-dependent, with upregulation of glycolytic pathways that contributed to neuronal survival and increased EPO production that supported vessel formation. ${ }^{115}$ A similar result was obtained by Hölscher et al ${ }^{116}$ when using a cardiomyocyte-specific deletion of PHD2 in a model of myocardial ischemia. Interestingly, this group also observed an increase in capillary size, but not in the number of capillaries, consistent with unchanged levels of proangiogenic factors. ${ }^{116}$

Recent work also showed that PHD2 inhibition enhanced progenitor cells function and skewed human bone marrowderived mesenchymal stem cells toward a proangiogenic phenotype, increasing their therapeutic potential. Furthermore, silencing of this protein restored diabetes-induced impairment of adaptive vascular response in a type 1 diabetic mouse model of chronic limb ischemia, enhancing neovascularization postischemia in a HIF $1 \alpha$-dependent manner. ${ }^{117}$

The formation of new blood vessels and remodeling of preexisting collateral arterioles occurs upon ischemia to reestablish the blood flow to the tissue. During this process, endothelial cells secrete VEGF that in turn induces the production of chemokine (C-C Motif) ligand 2 by the endothelial cells or smooth muscle cells, with monocyte recruitment to the ischemic area. These cells in turn induce the motility and proliferation of the smooth muscle cells through the production of growth factors. ${ }^{118}$ Therefore, the role of PHD2 in the inflammatory cells has also been the target of several studies.

Takeda et $\mathrm{al}^{119}$ observed that macrophages expressing low levels of PHD2 display an arteriogenic phenotype, leading to collateral vessel formation and protection of the skeletal muscle from necrosis in a model of hind-limb ischemia. This outcome was the result of an increased expansion of M2-like macrophages in the tissue and their increased release of proarteriogenic factors, leading to increased smooth muscle cell recruitment and growth. This preconditioning was not dependent on the HIF pathway activation, but on the activation of the canonical NFKB pathway in these cells. ${ }^{119}$ Further work from this group described this mechanism under ischemic conditions, showing that in these circumstances, ANG1-TIE2 signaling represses PHD2 transcription and therefore leads to the activation of NFKB. ${ }^{120}$

Deletion of PHD2 in the myeloid cells upon hypertensive vascular and cardiac remodeling was also shown to attenuate these processes as it impairs the migration and infiltration of macrophages into the tissue while reducing the production of proinflammatory and profibrotic mediators by these cells. ${ }^{121} \mathrm{It}$ was speculated that this outcome is dependent on the downregulation of TGF- $\beta$ levels produced by the macrophages by the stabilization of HIF, a mechanism previously described in endothelial cells. ${ }^{122}$

Overall, PHD2 seems to have a detrimental role upon tissue ischemia mainly through the inhibition of the HIF pathway. Although several studies have observed a similar outcome upon PHD2 inhibition, the mechanism through which PHD2 exerts its functions is not well characterized and seems to be cell-type dependent.

\section{Wound healing}

During the process of wound healing, the skin becomes more hypoxic due to the vascular disruption and increased oxygen consumption by the cells that outlie the wound. Wound healing comprises inflammatory, angiogenic, and reepithealization processes that involve several distinct cell types and mediators. The hypoxic environment created throughout the healing leads to the activation of the HIF pathway. HIF $1 \alpha$ has been shown to play an important role during wound healing, as loss of this isoform in keratinocytes was shown to delay this process. ${ }^{123}$ Indeed, our lab has demonstrated that PHD2 deletion specifically in the keratinocytes improves the wound healing capacity by inducing the migration of these cells in the wound area, mediated by HIF $1 \alpha$-induction of 
$\beta_{3}$-integrin, with parallel enhanced proliferation in a TGF $\beta$ dependent manner. Keratinocytes lacking PHD2 showed suppressed TGF $\beta$ signaling, with consequent decreased inhibition of their proliferation when compared with WT counterparts. ${ }^{124}$

The role of PHD2 during wound healing has also been assessed in fibroblasts, as these cells have a major role in breaking down the fibrin clot and creating new extracellular matrix and collagen fibers that give the required support to other cells. In a model of diabetic wound, implantation of PHD2-silenced fibroblasts improved the healing of the diabetic wound, and silencing of PHD2 in these cells increased the levels of HIF $1 \alpha$ and VEGF, inducing the proliferation of fibroblasts and new capillary formation in the wound area. ${ }^{125}$

Furthermore, Wetterau et al ${ }^{126}$ observed the induction of therapeutic angiogenesis upon topical treatment of a mouse diabetic wound with PHD2 siRNA, and Vandegrift et al ${ }^{127}$ obtained a similar outcome when treating mouse dorsal wounds with siRNA delivered in an acellular dermal matrix form. Therapies involving the use of local PHD2 inhibitors could, therefore, accelerate the wound healing procedure.

\section{Asthma}

During the allergic inflammation that occurs in asthma, a hypoxic environment is created. Cells respond to the shortage of $\mathrm{O}_{2}$ through the activation of the HIF pathway, which perpetuates the highly proinflammatory response and consequent aggravation of the disease outcome. Furthermore, bronchial biopsies of asthmatic patients reveal increased activation of the HIF pathway. ${ }^{128}$ The activation of the HIF $1 \alpha$ subunit has a proinflammatory connotation and leads to the activation of genes, such as $V E G F$, which are implicated in airway remodeling. This pathway has also been associated with increased collagen synthesis and fibrosis. ${ }^{129}$

Several studies have found increased levels of both HIF $1 \alpha$ and PHD2 in animal models of asthma. Using a nonspecific HIF1 inhibitor, Huerta-Yepez et al ${ }^{130}$ have reported that the inhibition of this pathway reduced the allergic inflammation and lung remodeling in an ovalbumin-triggered mouse model. Furthermore, inhibition of PHD2 by ethyl 3,4-dihydroxybenzoic acid, an oxoglutarate analog, has been shown to lead to a dose-dependent increase of airway hyperresponsiveness in a mouse model of asthma, associated with an increased cell infiltration, mucus production, and collagen deposition in the basal membrane of the epithelium. ${ }^{129}$ Although this data points to a possible protective role of PHD2 in the development of asthma, not much is known regarding the mechanism through which PHD2 seems to mediate these effects.

\section{Obesity}

In obesity, the adipose tissue expansion that occurs is associated with a decrease in oxygen pressure in the tissue due to an inadequate vascular response. The hypoxia that ensues is associated with local inflammation, fibrosis, and metabolic dysfunction, resulting in a detrimental outcome to the patient. Interestingly, studies on the role of PHD2 in this condition have suggested a detrimental role of this protein during obesity. While Matsuura et al ${ }^{131}$ observed that deletion of PHD2 in adipocytes attenuated weight gain and alleviated the glucose intolerance that occurs during a high-fat diet model, with reduced fat mass and lower macrophage infiltration into the white adipose tissue, Michailidou et a $1^{132}$ showed an increased adipose mass in adipose-specific PHD2-knockout mice. Notwithstanding the disparity in adipose mass, this group also observed a normal glucose tolerance in these mice, with reduced levels of circulating fatty acids and no increase in macrophage levels in the white adipose tissue. ${ }^{132}$ The available body of data on the role of PHD2 in obesity is, however, scarce and further work needs to be pursued to underlie the mechanisms responsible for this outcome.

\section{Conclusion}

The role of PHD2 as the major regulator of the hypoxic response has been widely accepted and characterized in the last years. Furthermore, accumulating evidence indicates the influence of this protein in the regulation of an extensive array of physiological and pathological effects, involving the control of the HIF pathway and other distinct pathways or mechanisms. Although the additional roles of PHD2 are still somewhat elusive, the discovery of multiple interactors raises the possibility that PHD2 will be involved in many biological responses.

The use of PHD2-conditional-deficient mouse models has broadened our knowledge on the protective role of this enzyme during physiological processes such as erythropoiesis. On the other hand, during pathological disorders (including a majority of cancer types, ischemia, as well as skin wound healing), PHD2 is often a detrimental factor. This shows the importance of this enzyme in biological processes, but underscores at the same time its complexity. Therefore, further research in the cells that mediate these disorders is of utmost importance. Furthermore, the HIF prolyl hydroxylases are also the subject of pharmaceutical targeting by small-molecule inhibitors to activate or augment 
the endogenous HIF transcriptional response for treatment of hypoxic human diseases. ${ }^{40}$

\section{Acknowledgments}

Work in the lab of Ben Wielockx has been supported by grants from the DFG (WI 3291/1-1, 1-2, 3, and 5). AMM is funded by the Medical Faculty - (TU-Dresden, Germany) and BW is a Heisenberg Professor (DFG). We apologize to our colleagues whose work was not cited due to space limitations.

\section{Disclosure}

The authors report no conflicts of interest in this work.

\section{References}

1. Wenger RH, Kurtcuoglu V, Scholz CC, Marti HH, Hoogewijs D. Frequently asked questions in hypoxia research. $J$ Hypoxia. 2015;3:35-43.

2. Semenza GL, Wang GL. A nuclear factor induced by hypoxia via de novo protein synthesis binds to the human erythropoietin gene enhancer at a site required for transcriptional activation. Mol Cell Biol. 1992;12(12):5447-5454.

3. Wang GL, Jiang BH, Rue EA, Semenza GL. Hypoxia-inducible factor 1 is a basic-helix-loop-helix-PAS heterodimer regulated by cellular $\mathrm{O}_{2}$ tension. Proc Natl Acad Sci U S A. 1995;92(12):5510-5514.

4. Semenza GL, Jiang BH, Leung SW, et al. Hypoxia response elements in the aldolase A, enolase 1, and lactate dehydrogenase A gene promoters contain essential binding sites for hypoxia-inducible factor 1. $J$ Biol Chem. 1996;271(51):32529-32537.

5. Mole DR, Blancher C, Copley RR, et al. Genome-wide association of hypoxia-inducible factor (HIF)- $1 \alpha$ and HIF-2 $\alpha$ DNA binding with expression profiling of hypoxia-inducible transcripts. J Biol Chem. 2009;284(25):16767-16775.

6. Kim JW, Tchernyshyov I, Semenza GL, Dang CV. HIF-1-mediated expression of pyruvate dehydrogenase kinase: a metabolic switch required for cellular adaptation to hypoxia. Cell Metab. 2006;3(3):177-185.

7. Wiesener MS, Jürgensen JS, Rosenberger C, et al. Widespread hypoxia-inducible expression of HIF- $2 \alpha$ in distinct cell populations of different organs. FASEB J Off Publ Fed Am Soc Exp Biol. 2003;17(2):271-273.

8. Hu CJ, Wang LY, Chodosh LA, Keith B, Simon MC. Differential roles of hypoxia-inducible factor $1 \alpha$ (HIF-1 $\alpha$ ) and HIF- $2 \alpha$ in hypoxic gene regulation. Mol Cell Biol. 2003;23(24):9361-9374.

9. Ratcliffe PJ. HIF-1 and HIF-2: working alone or together in hypoxia? $J$ Clin Invest. 2007;117(4):862-865.

10. Semenza GL. Oxygen sensing, homeostasis, and disease. NEngl J Med. 2011;365(6):537-547.

11. Mahon PC, Hirota K, Semenza GL. FIH-1: a novel protein that interacts with HIF-1 $\alpha$ and VHL to mediate repression of HIF-1 transcriptional activity. Genes Dev. 2001;15(20):2675-2686.

12. Bruick RK, McKnight SL. A conserved family of prolyl-4-hydroxylases that modify HIF. Science. 2001;294(5545):1337-1340.

13. Pereira T, Zheng X, Ruas JL, Tanimoto K, Poellinger L. Identification of residues critical for regulation of protein stability and the transactivation function of the hypoxia-inducible factor- $1 \alpha$ by the von Hippel-Lindau tumor suppressor gene product. J Biol Chem. 2003;278(9):6816-6823.

14. Hirsilä M, Koivunen P, Günzler V, Kivirikko KI, Myllyharju J. Characterization of the human prolyl 4-hydroxylases that modify the hypoxia-inducible factor. J Biol Chem. 2003;278(33): 30772-30780.
15. Min JH, Yang H, Ivan M, Gertler F, Kaelin WG Jr, Pavletich NP. Structure of an HIF-1 $\alpha$-pVHL complex: hydroxyproline recognition in signaling. Science. 2002;296(5574):1886-1889.

16. Ivan M, Kondo K, Yang H, et al. HIF $\alpha$ targeted for VHL-mediated destruction by proline hydroxylation: implications for $\mathrm{O}_{2}$ sensing. Science. 2001;292(5516):464-468.

17. Jaakkola P, Mole DR, Tian YM, et al. Targeting of HIF- $\alpha$ to the von Hippel-Lindau ubiquitylation complex by $\mathrm{O}_{2}$-regulated prolyl hydroxylation. Science. 2001;292(5516):468-472.

18. Maxwell PH, Wiesener MS, Chang GW, et al. The tumour suppressor protein VHL targets hypoxia-inducible factors for oxygen-dependent proteolysis. Nature. 1999;399(6733):271-275.

19. Epstein AC, Gleadle JM, McNeill LA, et al. C. elegans EGL-9 and mammalian homologs define a family of dioxygenases that regulate HIF by prolyl hydroxylation. Cell. 2001;107(1):43-54.

20. Schödel J, Oikonomopoulos S, Ragoussis J, Pugh CW, Ratcliffe PJ, Mole DR. High-resolution genome-wide mapping of HIF-binding sites by ChIP-seq. Blood. 2011;117(23):e207-e217.

21. Semenza GL. Oxygen sensing, hypoxia-inducible factors, and disease pathophysiology. Annu Rev Pathol Mech Dis. 2014;9(1):47-71.

22. Lee KE, Simon MC. SnapShot: hypoxia-inducible factors. Cell. 2015;163(5):1288.e1-1288.e1.

23. Schofield CJ, Ratcliffe PJ. Oxygen sensing by HIF hydroxylases. Nat Rev Mol Cell Biol. 2004;5(5):343-354.

24. Schofield CJ, Zhang Z. Structural and mechanistic studies on 2-oxoglutarate-dependent oxygenases and related enzymes. Curr Opin Struct Biol. 1999;9(6):722-731.

25. Rabinowitz MH. Inhibition of hypoxia-inducible factor prolyl hydroxylase domain oxygen sensors: tricking the body into mounting orchestrated survival and repair responses. J Med Chem. 2013;56(23):9369-9402.

26. Jokilehto T, Jaakkola PM. The role of HIF prolyl hydroxylases in tumour growth. J Cell Mol Med. 2010;14(4):758-770.

27. Metzen E, Berchner-Pfannschmidt U, Stengel P, et al. Intracellular localisation of human HIF-1 $\alpha$ hydroxylases: implications for oxygen sensing. J Cell Sci. 2003;116(Pt 7):1319-1326.

28. Huang J, Zhao Q, Mooney SM, Lee FS. Sequence determinants in hypoxia-inducible factor- $1 \alpha$ for hydroxylation by the prolyl hydroxylases PHD1, PHD2, and PHD3. J Biol Chem. 2002;277(42): 39792-39800.

29. Steinhoff A, Pientka FK, Mockel S, et al. Cellular oxygen sensing: importins and exportins are mediators of intracellular localisation of prolyl-4-hydroxylases PHD1 and PHD2. Biochem Biophys Res Commun. 2009;387(4):705-711.

30. Yasumoto K, Kowata Y, Yoshida A, Torii S, Sogawa K. Role of the intracellular localization of HIF-prolyl hydroxylases. Biochim Biophys Acta. 2009;1793(5):792-797.

31. Appelhoff RJ, Tian YM, Raval RR, et al. Differential function of the prolyl hydroxylases PHD1, PHD2, and PHD3 in the regulation of hypoxia-inducible factor. $J$ Biol Chem. 2004;279(37):38458-38465.

32. Zhang Q, Gu J, Li L, et al. Control of cyclin D1 and breast tumorigenesis by the EglN2 prolyl hydroxylase. Cancer Cell. 2009;16(5):413-424.

33. Katschinski DM. In vivo functions of the prolyl-4-hydroxylase domain oxygen sensors: direct route to the treatment of anaemia and the protection of ischaemic tissues. Acta Physiol (Oxf). 2009;195(4): 407-414.

34. Mollenhauer M, Kiss J, Dudda J, et al. Deficiency of the oxygen sensor PHD1 augments liver regeneration after partial hepatectomy. Langenbecks Arch Surg. 2012;397(8):1313-1322.

35. Tambuwala MM, Cummins EP, Lenihan CR, et al. Loss of prolyl hydroxylase-1 protects against colitis through reduced epithelial cell apoptosis and increased barrier function. Gastroenterology. 2010;139(6):2093-2101.

36. Minamishima YA, Moslehi J, Bardeesy N, Cullen D, Bronson RT, Kaelin WG Jr. Somatic inactivation of the PHD2 prolyl hydroxylase causes polycythemia and congestive heart failure. Blood. 2008;111(6):3236-3244. 
37. Singh RP, Franke K, Kalucka J, et al. HIF prolyl hydroxylase 2 (PHD2) is a critical regulator of hematopoietic stem cell maintenance during steady-state and stress. Blood. 2013;121(26):5158-5166.

38. Takeda K, Cowan A, Fong GH. Essential role for prolyl hydroxylase domain protein 2 in oxygen homeostasis of the adult vascular system. Circulation. 2007;116(7):774-781.

39. Takeda K, Aguila HL, Parikh NS, et al. Regulation of adult erythropoiesis by prolyl hydroxylase domain proteins. Blood. 2008;111(6):3229-3235.

40. Chan MC, Holt-Martyn JP, Schofield CJ, Ratcliffe PJ. Pharmacological targeting of the HIF hydroxylases - a new field in medicine development. Mol Aspects Med. 2016;47-48:54-75.

41. Selak MA, Armour SM, MacKenzie ED, et al. Succinate links TCA cycle dysfunction to oncogenesis by inhibiting HIF- $\alpha$ prolyl hydroxylase. Cancer Cell. 2005;7(1):77-85.

42. Wong BW, Kuchnio A, Bruning U, Carmeliet P. Emerging novel functions of the oxygen-sensing prolyl hydroxylase domain enzymes. Trends Biochem Sci. 2013;38(1):3-11.

43. Li Y, Zhang D, Wang X, et al. Hypoxia-inducible miR-182 enhances HIF $1 \alpha$ signaling via targeting PHD2 and FIH1 in prostate cancer. $S c i$ Rep. 2015;5:12495.

44. Barth S, Edlich F, Berchner-Pfannschmidt U, et al. Hypoxiainducible factor prolyl-4-hydroxylase PHD2 protein abundance depends on integral membrane anchoring of FKBP38. J Biol Chem. 2009;284(34):23046-23058.

45. Aprelikova O, Pandolfi S, Tackett S, et al. Melanoma antigen-11 inhibits the hypoxia-inducible factor prolyl hydroxylase 2 and activates hypoxic response. Cancer Res. 2009;69(2):616-624.

46. D’Angelo G, Duplan E, Boyer N, Vigne P, Frelin C. Hypoxia up-regulates prolyl hydroxylase activity: a feedback mechanism that limits HIF-1 responses during reoxygenation. $J$ Biol Chem. 2003;278(40):38183-38187.

47. EGLN1 (PNAS-118) Result Summary | BioGRID. Available from: http://thebiogrid.org/120060/summary/homo-sapiens/egln1.html Accessed March 3, 2016.

48. Baek JH, Mahon PC, Oh J, et al. OS-9 interacts with hypoxia-inducible factor $1 \alpha$ and prolyl hydroxylases to promote oxygen-dependent degradation of HIF-1 $\alpha$. Mol Cell. 2005;17(4):503-512.

49. Foxler DE, Bridge KS, James V, et al. The LIMD1 protein bridges an association between the prolyl hydroxylases and VHL to repress HIF-1 activity. Nat Cell Biol. 2012;14(2):201-208.

50. Zhang CS, Liu Q, Li M, et al. RHOBTB3 promotes proteasomal degradation of HIF $\alpha$ through facilitating hydroxylation and suppresses the Warburg effect. Cell Res. 2015;25(9):1025-1042.

51. Park MH, Choi KY, Jung Y, Min DS. Phospholipase D1 protein coordinates dynamic assembly of HIF-1 $\alpha$-PHD-VHL to regulate HIF- $1 \alpha$ stability. Oncotarget. 2014;5(23):11857-11872.

52. Wong W, Goehring AS, Kapiloff MS, Langeberg LK, Scott JD. mAKAP compartmentalizes oxygen-dependent control of HIF-1 $\alpha$. Sci Signal. 2008;1(51):ra18

53. Choi YK, Kim JH, Kim WJ, et al. AKAP12 regulates human bloodretinal barrier formation by downregulation of hypoxia-inducible factor-1 $\alpha$. . N Neurosci. 2007;27(16):4472-4481.

54. Lee SH, Bae SC, Kim KW, Lee YM. RUNX3 inhibits hypoxiainducible factor- $1 \alpha$ protein stability by interacting with prolyl hydroxylases in gastric cancer cells. Oncogene. 2014;33(11): 1458-1467.

55. Colla S, Tagliaferri S, Morandi F, et al. The new tumor-suppressor gene inhibitor of growth family member 4 (ING4) regulates the production of proangiogenic molecules by myeloma cells and suppresses hypoxiainducible factor- $1 \alpha$ (HIF-1 $\alpha)$ activity: involvement in myeloma-induced angiogenesi. Blood. 2007;110(13):4464-4475.

56. Song D, Li LS, Heaton-Johnson KJ, Arsenault PR, Master SR, Lee FS. Prolyl hydroxylase domain protein 2 (PHD2) binds a Pro-Xaa-Leu-Glu motif, linking it to the heat shock protein 90 pathway. $J$ Biol Chem. 2013;288(14):9662-9674.
57. Cummins EP, Berra E, Comerford KM, et al. Prolyl hydroxylase-1 negatively regulates I $\kappa B$ kinase- $\beta$, giving insight into hypoxia-induced NFKB activity. Proc Natl Acad Sci U S A. 2006;103(48):18154-18159.

58. Chan DA, Kawahara TLA, Sutphin PD, Chang HY, Chi JT, Giaccia AJ. Tumor vasculature is regulated by PHD2-mediated angiogenesis and bone marrow-derived cell recruitment. Cancer Cell. 2009;15(6): $527-538$.

59. Romero-Ruiz A, Bautista L, Navarro V, et al. Prolyl hydroxylasedependent modulation of eukaryotic elongation factor 2 activity and protein translation under acute hypoxia. J Biol Chem. 2012;287(12): 9651-9658.

60. Moore CEJ, Mikolajek H, Regufe da Mota S, et al. Elongation factor 2 kinase is regulated by proline hydroxylation and protects cells during hypoxia. Mol Cell Biol. 2015;35(10):1788-1804.

61. Huo Z, Ye JC, Chen J, et al. Prolyl hydroxylase domain protein 2 regulates the intracellular cyclic AMP level in cardiomyocytes through its interaction with phosphodiesterase 4D. Biochem Biophys Res Commun. 2012;427(1):73-79.

62. Xie L, Pi X, Townley-Tilson WHD, et al. PHD2/3-dependent hydroxylation tunes cardiac response to $\beta$-adrenergic stress via phospholamban. J Clin Invest. 2015;125(7):2759-2771.

63. Lee DC, Sohn HA, Park ZY, et al. A lactate-induced response to hypoxia. Cell. 2015;161(3):595-609.

64. Kuznetsova AV, Meller J, Schnell PO, et al. von Hippel-Lindau protein binds hyperphosphorylated large subunit of RNA polymerase II through a proline hydroxylation motif and targets it for ubiquitination. Proc Natl Acad Sci U S A. 2003;100(5):2706-2711.

65. Mikhaylova O, Ignacak ML, Barankiewicz TJ, et al. The von HippelLindau tumor suppressor protein and Egl-9-type proline hydroxylases regulate the large subunit of RNA polymerase II in response to oxidative stress. Mol Cell Biol. 2008;28(8):2701-2717.

66. Yi Y, Mikhaylova O, Mamedova A, et al. von Hippel-Lindau-dependent patterns of RNA polymerase II hydroxylation in human renal clear cell carcinomas. Clin Cancer Res. 2010;16(21):5142-5152.

67. Franke K, Gassmann M, Wielockx B. Erythrocytosis: the HIF pathway in control. Blood. 2013;122(7):1122-1128.

68. Ikeda E. Cellular response to tissue hypoxia and its involvement in disease progression. Pathol Int. 2005;55(10):603-610.

69. Ebert BL, Bunn HF. Regulation of the erythropoietin gene. Blood. 1999;94(6):1864-1877.

70. Goldberg MA, Dunning SP, Bunn HF. Regulation of the erythropoietin gene: evidence that the oxygen sensor is a heme protein. Science. 1988;242(4884):1412-1415.

71. Kapitsinou PP, Liu Q, Unger TL, et al. Hepatic HIF-2 regulates erythropoietic responses to hypoxia in renal anemia. Blood. 2010;116(16):3039-3048

72. Al-Sheikh M, Moradkhani K, Lopez M, Wajcman H, Prehu C. Disturbance in the HIF-1 $\alpha$ pathway associated with erythrocytosis: further evidences brought by frameshift and nonsense mutations in the prolyl hydroxylase domain protein 2 (PHD2) gene. Blood Cells Mol Dis. 2008;40(2):160-165.

73. Ladroue C, Carcenac R, Leporrier M, et al. PHD2 mutation and congenital erythrocytosis with paraganglioma. $N$ Engl $J$ Med. 2008;359(25):2685-2692.

74. Percy MJ, Zhao Q, Flores A, et al. A family with erythrocytosis establishes a role for prolyl hydroxylase domain protein 2 in oxygen homeostasis. Proc Natl Acad Sci U S A. 2006;103(3):654-659.

75. Mazzone M, Dettori D, Leite de Oliveira R, et al. Heterozygous deficiency of PHD2 restores tumor oxygenation and inhibits metastasis via endothelial normalization. Cell. 2009;136(5):839-851.

76. Minamishima YA, Kaelin WGJ. Reactivation of hepatic EPO synthesis in mice after PHD loss. Science. 2010;329(5990):407.

77. Minamishima YA, Moslehi J, Padera RF, Bronson RT, Liao R, Kaelin WGJ. A feedback loop involving the Phd3 prolyl hydroxylase tunes the mammalian hypoxic response in vivo. Mol Cell Biol. 2009;29(21):5729-5741. 
78. Arsenault PR, Pei F, Lee R, et al. A knock-in mouse model of human PHD2 gene-associated erythrocytosis establishes a haploinsufficiency mechanism. J Biol Chem. 2013;288(47):33571-33584.

79. Franke K, Kalucka J, Mamlouk S, et al. HIF-1 $\alpha$ is a protective factor in conditional PHD2-deficient mice suffering from severe HIF-2 $\alpha$-induced excessive erythropoiesis. Blood. 2013;121(8): 1436-1445.

80. Tojo Y, Sekine H, Hirano I, et al. Hypoxia signaling cascade for erythropoietin production in hepatocytes. Mol Cell Biol. 2015;35(15):2658-2672.

81. Duan LJ, Takeda K, Fong GH. Hematological, hepatic, and retinal phenotypes in mice deficient for prolyl hydroxylase domain proteins in the liver. Am J Pathol. 2014;184(4):1240-1250.

82. Soni H. Prolyl hydroxylase domain-2 (PHD2) inhibition may be a better therapeutic strategy in renal anemia. Med Hypotheses. 2014;82(5):547-550.

83. Maxwell PH, Eckardt KU. HIF prolyl hydroxylase inhibitors for the treatment of renal anaemia and beyond. Nat Rev Nephrol. 2015; 12(3):157-168.

84. Brigandi RA, Johnson B, Oei C, et al. A novel hypoxia-inducible factor - prolyl hydroxylase inhibitor (GSK1278863) for anemia in CKD: a 28-day, phase 2A randomized trial. Am J Kidney Dis. Epub January 27, 2016.

85. Fu Q, Colgan SP, Shelley CS. Hypoxia: the force that drives chronic kidney disease. Clin Med Res. Epub February 4, 2016.

86. Shoji K, Tanaka T, Nangaku M. Role of hypoxia in progressive chronic kidney disease and implications for therapy. Curr Opin Nephrol Hypertens. 2014;23(2):161-168.

87. Tanaka T, Nangaku M. Angiogenesis and hypoxia in the kidney. Nat Rev Nephrol. 2013;9(4):211-222.

88. Wang Z, Zhu Q, Li PL, et al. Silencing of hypoxia-inducible factor- $1 \alpha$ gene attenuates chronic ischemic renal injury in two-kidney, one-clip rats. Am J Physiol Renal Physiol. 2014;306(10):F1236-F1242.

89. Casazza A, Di Conza G, Wenes M, Finisguerra V, Deschoemaeker S, Mazzone M. Tumor stroma: a complexity dictated by the hypoxic tumor microenvironment. Oncogene. 2014;33(14):1743-1754.

90. Hanahan D, Weinberg RA. The hallmarks of cancer. Cell. 2000; 100(1):57-70.

91. Gray LH, Conger AD, Ebert M, Hornsey S, Scott OC. The concentration of oxygen dissolved in tissues at the time of irradiation as actor in radiotherapy. Br J Radiol. 1953;26(312):638-648.

92. Thomlinson RH, Gray LH. The histological structure of some human lung cancers and the possible implications for radiotherapy. $\mathrm{Br} J$ Cancer. 1955;9(4):539-549.

93. Brown JM, Wilson WR. Exploiting tumour hypoxia in cancer treatment. Nat Rev Cancer. 2004;4(6):437-447.

94. Vaupel P, Mayer A. Hypoxia in cancer: significance and impact on clinical outcome. Cancer Metastasis Rev. 2007;26(2):225-239.

95. Bertout JA, Patel SA, Simon MC. The impact of $\mathrm{O}_{2}$ availability on human cancer. Nat Rev Cancer. 2008;8(12):967-975.

96. Keith B, Johnson RS, Simon MC. HIF $1 \alpha$ and HIF $2 \alpha$ : sibling rivalry in hypoxic tumour growth and progression. Nat Rev Cancer. 2012;12(1):9-22.

97. Rhodes DR, Kalyana-Sundaram S, Mahavisno V, et al. Oncomine 3.0: genes, pathways, and networks in a collection of 18,000 cancer gene expression profiles. Neoplasia. 2007;9(2):166-180.

98. Rawluszko A, Bujnicka K, Horbacka K, Krokowicz P, Jagodzinski P. Expression and DNA methylation levels of prolyl hydroxylases PHD1, PHD2, PHD3 and asparaginyl hydroxylase FIH in colorectal cancer. BMC Cancer. 2013;13(1):526.

99. Xie G, Zheng L, Ou J, et al. Low expression of prolyl hydroxylase 2 is associated with tumor grade and poor prognosis in patients with colorectal cancer. Exp Biol Med. 2012;237(7):860-866.

100. Ladroue C, Hoogewijs D, Gad S, et al. Distinct deregulation of the hypoxia inducible factor by PHD2 mutants identified in germline DNA of patients with polycythemia. Haematologica. 2012;97(1):9-14.
101. Bordoli MR, Stiehl DP, Borsig L, et al. Prolyl-4-hydroxylase PHD2and hypoxia-inducible factor 2-dependent regulation of amphiregulin contributes to breast tumorigenesis. Oncogene. 2011;30(5): 548-560.

102. Wottawa M, Leisering P, Ahlen M von, et al. Knockdown of prolyl-4hydroxylase domain 2 inhibits tumor growth of human breast cancer MDA-MB-231 cells by affecting TGF- $\beta 1$ processing. Int J Cancer. 2013;132(12):2787-2798.

103. Naba A, Clauser KR, Lamar JM, Carr SA, Hynes RO. Extracellular matrix signatures of human mammary carcinoma identify novel metastasis promoters. Elife. 2014;3:e01308.

104. Kuchnio A, Moens S, Bruning U, et al. The cancer cell oxygen sensor PHD2 promotes metastasis via activation of cancer-associated fibroblasts. Cell Rep. 2015;12(6):992-1005.

105. Klotzsche-von Ameln A, Muschter A, Heimesaat MM, Breier G, Wielockx B. HIF prolyl hydroxylase-2 inhibition diminishes tumor growth through matrix metalloproteinase-induced TGF $\beta$ activation. Cancer Biol Ther. 2012;13(4):216-223.

106. Klotzsche-von Ameln A, Muschter A, Mamlouk S, et al. Inhibition of HIF prolyl hydroxylase-2 blocks tumor growth in mice through the antiproliferative activity of TGF $\beta$. Cancer Res. 2011;71(9):3306-3316.

107. Mamlouk S, Wielockx B. Hypoxia-inducible factors as key regulators of tumor inflammation. Int J Cancer. 2013;132(12):2721-2729.

108. Leite de Oliveira R, Deschoemaeker S, Henze AT, et al. Gene-targeting of Phd 2 improves tumor response to chemotherapy and prevents sidetoxicity. Cancer Cell. 2012;22(2):263-277.

109. Madsen CD, Pedersen JT, Venning FA, et al. Hypoxia and loss of PHD2 inactivate stromal fibroblasts to decrease tumour stiffness and metastasis. EMBO Rep. 2015;16(10):1394-1408.

110. Hanahan D, Weinberg RA. Hallmarks of cancer: the next generation. Cell. 2011;144(5):646-674.

111. Kumar V, Gabrilovich DI. Hypoxia-inducible factors in regulation of immune responses in tumour microenvironment. Immunology. 2014;143(4):512-519.

112. Dang EV, Barbi J, Yang HY, et al. Control of T(H)17/T(reg) balance by hypoxia-inducible factor 1. Cell. 2011;146(5):772-784.

113. Mamlouk S, Kalucka J, Singh RP, et al. Loss of prolyl hydroxylase-2 in myeloid cells and T-lymphocytes impairs tumor development. Int J Cancer. 2013;134(4):849-858

114. Natarajan R, Salloum FN, Fisher BJ, Kukreja RC, Fowler AA. Hypoxia inducible factor-1 activation by prolyl 4-hydroxylase-2 gene silencing attenuates myocardial ischemia reperfusion injury. Circ Res. 2006;98 (1):133-140.

115. Kunze R, Zhou W, Veltkamp R, Wielockx B, Breier G, Marti HH. Neuron-specific prolyl-4-hydroxylase domain 2 knockout reduces brain injury after transient cerebral ischemia. Stroke. 2012;43(10): 2748-2756.

116. Hölscher M, Silter M, Krull S, et al. Cardiomyocyte-specific prolyl4-hydroxylase domain 2 knock out protects from acute myocardial ischemic injury. J Biol Chem. 2011;286(13):11185-11194.

117. Howangyin KY, Loinard C, Bakker W, et al. HIF-prolyl hydroxylase 2 inhibition enhances the efficiency of mesenchymal stem cell-based therapies for the treatment of critical limb ischemia. Stem Cells. 2014;32:231-243.

118. Schirmer SH, van Nooijen FC, Piek JJ, van Royen N. Stimulation of collateral artery growth: travelling further down the road to clinical application. Heart. 2009;95(3):191-197.

119. Takeda Y, Costa S, Delamarre E, et al. Macrophage skewing by Phd2 haplodeficiency prevents ischaemia by inducing arteriogenesis. Nature. 2011;479(7371):122-126.

120. Hamm A, Veschini L, Takeda Y, et al. PHD2 regulates arteriogenic macrophages through TIE2 signalling. EMBO Mol Med. 2013; 5(6):843-857.

121. Ikeda J, Ichiki T, Matsuura H, et al. Deletion of phd 2 in myeloid lineage attenuates hypertensive cardiovascular remodeling. J Am Heart Assoc. 2013;2(3):e000178. 
122. Wei H, Bedja D, Koitabashi N, et al. Endothelial expression of hypoxiainducible factor 1 protects the murine heart and aorta from pressure overload by suppression of TGF- $\beta$ signaling. Proc Natl Acad Sci USA. 2012;109(14):E841-E850.

123. Rezvani HR, Ali N, Nissen LJ, et al. HIF-1 $\alpha$ in epidermis: oxygen sensing, cutaneous angiogenesis, cancer, and non-cancer disorders. J Invest Dermatol. 2011;131(9):1793-1805.

124. Kalucka J, Ettinger A, Franke K, et al. Loss of epithelial hypoxiainducible factor prolyl hydroxylase 2 accelerates skin wound healing in mice. Mol Cell Biol. 2013;33(17):3426-3438.

125. Zhang X, Yan X, Cheng L, et al. Wound healing improvement with PHD-2 silenced fibroblasts in diabetic mice. PLoS One. 2013;8(12):e84548.

126. Wetterau M, George F, Weinstein A, et al. Topical prolyl hydroxylase domain-2 silencing improves diabetic murine wound closure. Wound Repair Regen. 2011;19(4):481-486.

127. Vandegrift MT, Szpalski C, Knobel D, et al. Acellular dermal matrix-based gene therapy augments graft incorporation. J Surg Res. 2015;195(1):360-367.
128. Huerta-Yepez S, Baay-Guzman GJ, Bebenek IG, et al. Hypoxia inducible factor promotes murine allergic airway inflammation and is increased in asthma and rhinitis. Allergy. 2011;66(7):909-918.

129. Ahmad T, Kumar M, Mabalirajan U, et al. Hypoxia response in asthma: differential modulation on inflammation and epithelial injury. Am J Respir Cell Mol Biol. 2012;47(1):1-10.

130. Huerta-Yepez S, Baay-Guzman GJ, Garcia-Zepeda R, et al. 2-Methoxyestradiol (2-ME) reduces the airway inflammation and remodeling in an experimental mouse model. Clin Immunol. 2008;129(2):313-324.

131. Matsuura H, Ichiki T, Inoue E, et al. Prolyl hydroxylase domain protein 2 plays a critical role in diet-induced obesity and glucose intolerance. Circulation. 2013;127(21):2078-2087.

132. Michailidou Z, Morton NM, Moreno Navarrete JM, et al. Adipocyte pseudohypoxia suppresses lipolysis and facilitates benign adipose tissue expansion. Diabetes. 2015;64(3):733-745.
Hypoxia

\section{Publish your work in this journal}

Hypoxia is an international, peer-reviewed, open access journal that aims to improve understanding of the biological response to hypoxia. The journal will publish original research articles, reviews, methodological advances, clinical studies, and expert opinions that identify developments in the regulation of the physiological and pathological responses to

\section{Dovepress}

hypoxia and in the therapeutic targeting of hypoxia-responsive pathways The manuscript management system is completely online and includes a very quick and fair peer-review system, which is all easy to use. Visit http://www.dovepress.com/testimonials.php to read real quotes from published authors. 